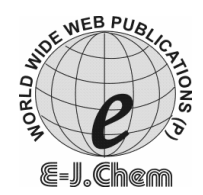

\title{
Production of Cellulose Nitrate Polymer from Sawdust
}

\author{
I.M ADEKUNLE \\ Department of Environmental Management and Toxicology, \\ University of Agriculture, P.M.B. 2240, Abeokuta, Nigeria. \\ imkunle@yahoo.com
}

Received 12 July 2009; Revised 5 October 2009; Accepted 3 December 2009

\begin{abstract}
Cellulose nitrate polymer was produced from sawdust of Nigeria origin using a method, which involved alternate alkaline and chlorination treatment to remove non-cellulosic constituents, followed by nitration reaction. The effects of nitrating acid mixture type and composition, nitrating time and nitrating acid mixture to cellulose material ratio on yield and solubility of products were investigated. Results showed that alkaline resistant $\alpha$-cellulose was extracted and the yield of cellulose nitrate ranged from 35.28 to $96.02 \%$, increasing with acid mixtures $\mathrm{HNO}_{3}+\mathrm{AC}_{2} \mathrm{O}+\mathrm{ACOH}<\mathrm{HNO}_{3}+\mathrm{H}_{2} \mathrm{SO}_{4}+\mathrm{H}_{2} \mathrm{O}$ $<\mathrm{HNO}_{3}+\mathrm{H}_{3} \mathrm{PO}_{4}+\mathrm{H}_{2} \mathrm{O}$. Variation in the composition of a particular nitrating acid mixture, relative acid strength of the nitrating mixture, nitrating time and proportion of nitrating acid to cellulose material all influenced the yield and solubility of cellulose nitrate whose nitrogen contents ranged from 11.06 to $13.12 \%$. The products were chloroform, acetone and ester soluble, hence, useful for industrial applications.
\end{abstract}

Keywords: Sawdust, Cellulose nitrate, Waste management, Environment.

\section{Introduction}

Sawdust as the name implies, consists of fine particles of wood produced from cutting with a saw. It is the main product of sawmills, a by-product from agricultural, forestry or architectural activities and can serve many useful purposes such as a mulch, fuel and sorbent material ${ }^{1}$. Despite the highlighted utilities, if not adequately utilized, sawdust, may constitute an environmental hazard. In Nigeria, the huge amount of sawdust materials generated are commonly combusted, abandoned or thrown into rivers, streams or drainages.

Sawdust thrown in water contributes to increased gross organic matter in the aquatic ecosystem, reflected by high biochemical oxygen demand and reduced dissolved oxygen. Depletion of oxygen in water will in turn lead to asphyxiation of fish and other aquatic organisms, a process that could result in poor hematological profile and body growth, 
productivity, species diversity or even death of these organisms ${ }^{2}$. Sawdust dumped in the terrestrial environment may build up into piles or heaps. Lignin, fatty acids and other toxic substances contained in sawdust leachates may then be released into nearby surface water or groundwater thereby deteriorating water quality ${ }^{3,4}$. The disposal of sawdust into the drainage leads to blockages, transforming the resulting stagnant water to breeding ground for pathogenic organisms with associated water related diseases and reduction of environmental aesthetics.

Sawdust is derived from either coniferous (softwood) or deciduous (hardwood) or a combination of both. Either way, different wood species may be structurally different but they are made up of basic chemical compositions such as cellulose, lignin, hemicelluloses and holocellulose ${ }^{5,6}$. Consequently, there is a potential to transform sawdust to a bioresource/feedstock for possible industrial applications.

For instance, by subjection to chemical treatments, sawdust could be converted to cellulosic polymers, which are useful raw materials for the production of explosives, lacquer and cellophanes. Cellulosic fibers made from sawdust are also utilized in the production of reinforced concrete pad, feed for livestock and bio-fuel and as sorbents for crude oil clean up. In Nigeria, cellulose acetate has been prepared from sawdust and feed for chicken formulated from cellulosic fiber extracted from sawdust ${ }^{7,8}$ but there is no readily available data on conversion to cellulose nitrate commonly referred to as nitrocellulose, which has a wide range of utility.

Depending on the nitrogen content, cellulose nitrate serves various purposes. It is utilized in the manufacture of gun cotton (nitrogen content of more than 13\%), an explosive that can be blended with other materials to obtain a powder that burns at desired speed. Others include pyroxylin of lower nitrogen content $(11-12 \%)$, highly inflammable but not explosive which is widely utilized in the manufacture of plastics and quick - drying lacquers. Celluloid is obtained by melting pyroxylin in three parts of ether and one part of alcohol. The addition of castor oil and camphor to celluloid yields flexible collodion that finds use in medical field for protective covering of minor cuts. Cellulose nitrate is also widely used in wood and paint industries ${ }^{5,9}$.

Pure cellulose, which is a principal raw material in the industrial production of cellulosic nitrate, being found in cotton, is extremely expensive leading to the high cost of the final product. The objective of this study was to investigate the potential of transformation of sawdust through chemical treatments to cellulose nitrate. Optimum nitrating conditions including nitrating acid mixture to cellulose material ratio, nitrating acid composition, acid strength and nitrating time were investigated and subsequent preparation of cellulosic nitrate polymer under the optimized conditions was carried out.

\section{Experimental}

The extraction procedure of Cross and Bevan, described by David and Nobuo ${ }^{9}$, which was based on chlorination and extraction with hot aqueous sodium sulphite was employed. Fine particulate sawdust (146 g) was boiled with $2 \%$ (w/v) sodium sulphate solution, followed by treatment with $4 \%, 10 \%$ and $18 \%$ sodium hydroxide $(\mathrm{NaOH})$ respectively for a duration of $2 \mathrm{~h}$ each and finally with $5 \%$ cold potassium hydroxide $(\mathrm{KOH})$ for $1 \mathrm{~h}$. The resulting residue (cellulosic pulp) was bleached with hypochlorite, rinsed with acetic acid and then thoroughly washed with distilled water. The cellulosic pulp was analyzed for yield, melting point and solubility in different concentrations (1.0, 5.0, 10.0, 17.5 and 20\%) of $\mathrm{NaOH}$. In 
order to test for the reactivity of the cellulosic fiber, $1.5 \mathrm{~g}$ of the cellulose was acetylated with $40 \mathrm{~mL}$ acetic anhydride $\left(\mathrm{Ac}_{2} \mathrm{O}\right)$ and glacial acetic acid $(\mathrm{AcOH})$ acidified with sulphuric acid $\left(\mathrm{H}_{2} \mathrm{SO}_{4}\right)$ at $60{ }^{\circ} \mathrm{C}$ in a water bath for 90 minutes. Excess $\mathrm{Ac}_{2} \mathrm{O}$ was destroyed with a mixture of water and $\mathrm{AcOH}$.

The precipitated cellulose acetate was filtered, washed with distilled water until neutral to litmus, oven dried at $60{ }^{\circ} \mathrm{C}$ to constant weight and then subjected to solubility test in ethanol $\left(\mathrm{C}_{2} \mathrm{H}_{5} \mathrm{OH}\right)$, acetone $\left(\left(\mathrm{CH}_{3}\right)_{2} \mathrm{CO}\right)$, pyridine $\left(\mathrm{C}_{5} \mathrm{H}_{5} \mathrm{~N}\right)$, methyl benzoate $\left(\mathrm{C}_{6} \mathrm{H}_{5} \mathrm{COOCH} 3\right)$, 1, 4-dioxane $\left(\mathrm{CH}_{2} \mathrm{CH}_{2} \mathrm{OCH}_{2} \mathrm{CH}_{2} \mathrm{CH}_{2} \mathrm{O}\right)$, chloroform $\left(\mathrm{CHCl}_{3}\right)$, phenol $\left(\mathrm{C}_{6} \mathrm{H}_{5} \mathrm{OH}\right)$ and anisole $\left(\mathrm{CH}_{3} \mathrm{OC}_{6} \mathrm{H}_{5}\right)$ at room temperature and with slight heating. The yield and melting point were also determined using standard procedures.

\section{Production of cellulose nitrate}

The effects of nitrating acid mixture to cellulose material ratio, acid strength, composition of a given nitrating acid mixture and nitrating time on yield of cellulose nitrate (nitrocellulose) were investigated. $\mathrm{HNO}_{3}$ is the nitrating agent, hence using nitric acid/ sulphuric acid/ water $\left(\mathrm{HNO}_{3}+\right.$ $\mathrm{H}_{2} \mathrm{SO}_{4}+\mathrm{H}_{2} \mathrm{O}$ ) acid mixture (a) only, the effect of nitrating acid-cellulose material ratio (20:1, 40:1, 50:1, 60:1, 80:1 and 100:1) was studied. Acid strength effect was then examined by substituting $\mathrm{H}_{2} \mathrm{SO}_{4}$ with phosphoric acid $\left(\mathrm{H}_{3} \mathrm{PO}_{4}\right)$ to give the $\mathrm{HNO}_{3}+\mathrm{H}_{3} \mathrm{PO}_{4}+\mathrm{H}_{2} \mathrm{O}$ mixture (b). Replacing $\mathrm{H}_{2} \mathrm{SO}_{4}$ and $\mathrm{H}_{2} \mathrm{O}$ with $\mathrm{AC}_{2} \mathrm{O}$ and $\mathrm{ACOH}$, the third nitrating acid mixture $\left[\mathrm{HNO}_{3}+\mathrm{AC} 2 \mathrm{O}+\mathrm{ACOH}\right.$ mixture (c)] was obtained. The effect of nitrating time was studied at 60 and 90 minutes using the three acid mixtures ( $a, b$ and $c$ ). The composition of each acid mixture was later varied and nitration was finally carried out under the optimized conditions (at constant nitrating acid to cellulose ratio, nitrating time, acid mixture composition) for each of the three acid mixtures.

The basic steps involved in the nitrating acid preparation were as follows: the appropriate weight $\left(\mathrm{W}_{\mathrm{a}}\right)$ of each of the acid mixture component was chosen, the sum of which formed the total weight $\left(\mathrm{W}_{\mathrm{A}}\right)$ of the acid mixture. The percentage composition $\left(\mathrm{Wa} / \mathrm{W}_{\mathrm{A}} \times 100\right)$ of each component was then calculated. To get the equivalent of $\mathrm{Wa}$ in volume, the percentage purity and specific gravity of the acid were taken into consideration.

\section{Nitration procedure}

Generally, a calculated volume (17.5 to $48.25 \mathrm{~mL}$ ) as the case may be, of prepared and cooled nitrating acid mixture was transferred to a calibrated burette. A known weight $(1.5 \mathrm{~g})$ of the pre-dried and ground cellulosic fiber was added into a conical flask and the nitrating acid mixture was added from a burette accompanied by stirring using a magnetic stirrer. The nitration period was between 60 to 90 minutes as was required, at an average reaction temperature of $15{ }^{\circ} \mathrm{C}$. At the end of nitration, cellulosic residue was separated by vacuum filtration. The filtrate was allowed to stand overnight for maximum reaction after which the spent acid was separated by centrifugation (Gallenkamp centrifuge) at 1, $400 \mathrm{rpm}$ for 10 minutes. Each nitration procedure was carried out in 3 replicates.

\section{Purification and chemical characterization of cellulose nitrate}

The solid product was severally washed with distilled water and filtered under centrifugal force at 1, $400 \mathrm{rpm}$ for 10 minutes. The cellulose nitrate was stabilized with boiling water for $3 \mathrm{~h}$ under reflux in a round bottom quick fit flask. The sample was then washed with cold water $\left(0{ }^{\circ} \mathrm{C}\right)$, dehydrated with suction and finally oven dried at $50{ }^{\circ} \mathrm{C}$ to constant weight. Yield, melting point, solubility tests were carried out using standard procedures. Qualitative test for nitrogen was conducted using Lassaigne sodium fusion test, followed by quantification using micro-Kjeldahl method ${ }^{10}$. 


\section{Statistical analysis}

Using the SPSS statistical package version 15.0 for Windows, 2007, the relationship between the nitrating acid to cellulose material ratio was established using Pearson correlation and one-way analysis of variance was used to investigate the variations in the yields obtained from the different nitrating acid mixtures. $T$-test was then performed on the yields obtained at the two nitrating times for each nitrating acid mixture.

\section{Results and Discussion}

The yields, melting points and moisture contents for the cellulose pulp and cellulose acetate were $35.92 \pm 5.6 \% ; 340$ to $350{ }^{\circ} \mathrm{C} ; 26 \pm 3 \%$ and $63.42 \pm 5.6 \% ; 303$ to $305{ }^{\circ} \mathrm{C} ; 22 \pm 1 \%$ respectively. The products obtained from $\mathrm{HNO}_{3}+\mathrm{H}_{2} \mathrm{SO}_{4}+\mathrm{H}_{2} \mathrm{O}$ was spongy but $\mathrm{HNO}_{3}+\mathrm{H}_{3} \mathrm{PO}_{4}+\mathrm{H}_{2} \mathrm{O}$ and $\mathrm{HNO}_{3}+\mathrm{AC}_{2} \mathrm{O}+\mathrm{ACOH}$ gave gelatinous products. The extracted cellulose was insoluble in all the concentrations of $\mathrm{NaOH}$ (cold or hot). Cellulose acetate was insoluble in benzene, dichloromethane, phenol and anisole but sparingly soluble in 1,4-dioxan. However, it was very soluble in either hot or cold chloroform, tetrachloromethane and acetone.

The effect of nitrating acid mixture to cellulose material ratio showed that the yields of cellulose nitrate varied from 12.2 to $56.38 \%$ with ratio 50:1 producing the highest yield. The yield, relative to nitrating acid mixture to cellulose material ratio, decreased in the order 50:1 > 80:1 > 60: $1>$ 100: $1>$ 40:1 > 20:1. The correlation between the material ratios and yields showed a direct relationship $(\mathrm{r}=0.694 ; \mathrm{P}>0.10)$. Acid strength effect, presented in Figure 1, showed that substituting $\mathrm{H}_{2} \mathrm{SO}_{4}$ with $\mathrm{H}_{3} \mathrm{PO}_{4}$ increased the mean yield of cellulose nitrate by $18.16 \%$ (from $71.13 \pm 4.58$ to $84.05 \pm 8.72 \%$ ) but replacing $\mathrm{H}_{2} \mathrm{SO}_{4}$ with acetic anhydride in acetic acid reduced the yield by $50.40 \%$ (from $71.13 \pm 4.58$ to $35.28 \pm 5.10 \%$ ) .

Results on nitrating time effect (Figure 2), showed that for the three nitrating acid mixtures, nitration at 90 minutes gave better yield of cellulose nitrate than nitration time of 60 minutes, however, only the yields from $\mathrm{HNO}_{3}+\mathrm{H}_{3} \mathrm{PO}_{4}+\mathrm{H}_{2} \mathrm{O}$ nitrating acid mixture was significantly $(\mathrm{p}<$ 0.10 ) different at the two nitrating periods. Under the optimized conditions (Figure 3), $\mathrm{HNO}_{3}+\mathrm{H}_{3} \mathrm{PO}_{4}+\mathrm{H}_{2} \mathrm{O}$ nitrating acid mixture gave the highest yield of $98 \pm 2 \%$ compared to $78 \pm 1 \%$ and $40.88 \pm 2.1 \%$ obtained for $\mathrm{HNO}_{3}+\mathrm{H}_{2} \mathrm{SO}_{4}+\mathrm{H}_{2} \mathrm{O}$ and $\mathrm{HNO}_{3}+\mathrm{AC}_{2} \mathrm{O}+\mathrm{ACOH}$ nitrating acid mixtures respectively.

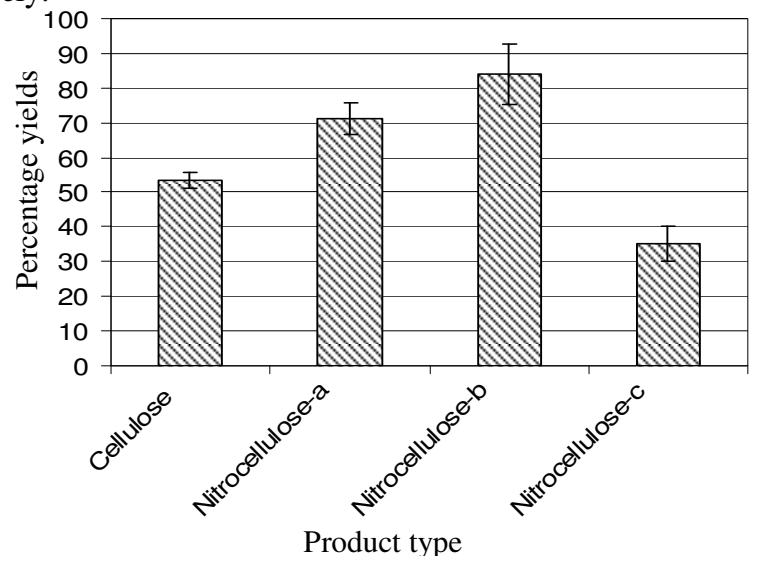

Figure 1. Yield of cellulose and acid strength effect on the yield of cellulose nitrate from sawdust, with the alphabets $\left(\mathrm{a}=\mathrm{HNO}_{3}+\mathrm{H}_{2} \mathrm{SO}_{4}+\mathrm{H}_{2} \mathrm{O}, \mathrm{b}=\mathrm{HNO}_{3}+\mathrm{H}_{3} \mathrm{PO}_{4}+\mathrm{H}_{2} \mathrm{O}, \mathrm{c}=\mathrm{HNO}_{3}+\right.$ $\left.\mathrm{AC}_{2} \mathrm{O}+\mathrm{ACOH}\right)$ representing the nitrating acid mixtures used in the nitrocellulose preparation. 


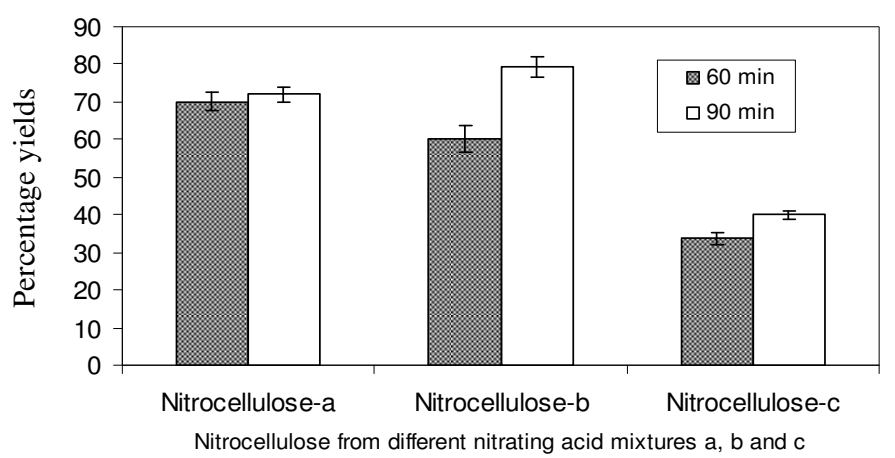

Figure 2. Effect of nitrating time on yield of cellulose nitrate prepared from sawdust, with the alphabets $\left(\mathrm{a}=\mathrm{HNO}_{3}+\mathrm{H}_{2} \mathrm{SO}_{4}+\mathrm{H}_{2} \mathrm{O}, \mathrm{b}=\mathrm{HNO}_{3}+\mathrm{H}_{3} \mathrm{PO}_{4}+\mathrm{H}_{2} \mathrm{O}, \mathrm{c}=\mathrm{HNO}_{3}+\mathrm{AC}_{2} \mathrm{O}+\right.$ $\mathrm{ACOH})$ representing the nitrating acid mixtures used in the nitrocellulose preparation.

Solubility of cellulose nitrate produced from sawdust as influenced by nitrating acid mixture type and composition is presented in Table 1 . All products were very soluble in pyridine and were either sparingly soluble in cold ester (methyl benzoate) or very soluble when the ester was slightly heated, very insoluble in benzene and ethanol. Except for the cellulose nitrate from $\mathrm{HNO}_{3}+\mathrm{AC}_{2} \mathrm{O}+\mathrm{ACOH}$, the others were soluble in acetone. The mean value of nitrogen contents of the cellulose nitrates are given in Table 2. Values ranged from 11.77 to $11.2 \%, 13.06$ to $12.40 \%$ and 13.12 to $13.00 \%$ for cellulose nitrates produced from $\mathrm{HNO}_{3}+$ $\mathrm{AC}_{2} \mathrm{O}+\mathrm{ACOH}, \mathrm{HNO}_{3}+\mathrm{H}_{2} \mathrm{SO}_{4}+\mathrm{H}_{2} \mathrm{O}$ and $\mathrm{HNO}_{3}+\mathrm{H}_{3} \mathrm{PO}_{4}+\mathrm{H}_{2} \mathrm{O}$ respectively.

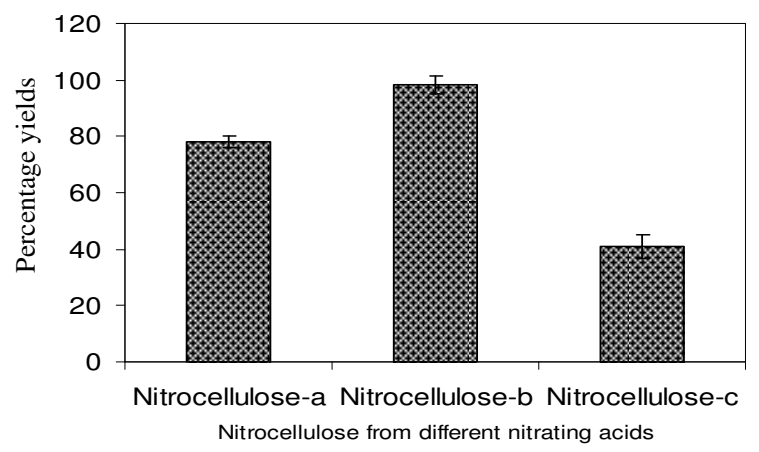

Figure 3. Yield of nitrocellulose produced from sawdust under the optimized conditions of constant nitrating acid to cellulose material ratio, nitrating time, composition of acid mixture, with the alphabets $\left(\mathrm{a}=\mathrm{HNO}_{3}+\mathrm{H}_{2} \mathrm{SO}_{4}+\mathrm{H}_{2} \mathrm{O}, \mathrm{b}=\mathrm{HNO}_{3}+\mathrm{H}_{3} \mathrm{PO}_{4}+\mathrm{H}_{2} \mathrm{O}, \mathrm{c}=\mathrm{HNO}_{3}+\mathrm{AC}_{2} \mathrm{O}\right.$ $+\mathrm{ACOH})$ representing the nitrating acid mixtures used in the nitrocellulose preparation.

The Cross and Bevan extraction was chosen for this study because the characteristic red or brown color formed with the chlorinated lignin served as end point to indicate complete removal of lignin, preventing over chlorination that decreases yield. Chlorination was adopted because chlorine reacts with lignin to form oxidized products which are soluble in aqueous alkaline solutions or sodium sulfite solution. However, because the crude extract contained some impurities (hemicelluloses), purification had to be carried out using sodium and potassium hydroxide at different concentrations and temperatures. The cellulose type used in this study was $\alpha$ - cellulose, which is defined as the residue that is insoluble in sodium hydroxide especially at concentrations $>$ $18 \%$. The fraction that solubilizes in the alkaline medium consists of $\beta$ - and $\gamma$-celluloses but on neutralization, $\beta$-cellulose precipitates while $\gamma$-cellulose remains in solution ${ }^{9,11,12}$. 
Table 1. Solubility of cellulose acetate and effect of nitrating acid composition on yield and solubility of cellulose nitrate produced from sawdust

\begin{tabular}{|c|c|c|c|c|c|c|c|c|c|c|c|c|c|c|c|}
\hline \multicolumn{16}{|c|}{ Solubility of cellulose acetate in different solvents } \\
\hline \multicolumn{2}{|c|}{ Dichloromethane } & \multicolumn{2}{|c|}{ Tetrachloromethane } & \multicolumn{2}{|c|}{ Chloroform } & \multicolumn{2}{|c|}{ Benzene } & \multicolumn{2}{|c|}{ Acetone } & \multicolumn{2}{|c|}{ Phenol } & \multicolumn{2}{|c|}{ Pyridine } & \multicolumn{2}{|c|}{ 1, 4-dioxan } \\
\hline C & $\mathrm{H}$ & $\mathrm{C}$ & $\mathrm{H}$ & $\mathrm{C}$ & $\mathrm{H}$ & $\mathrm{C}$ & $\mathrm{H}$ & $\mathrm{C}$ & $\mathrm{H}$ & $\mathrm{C}$ & $\mathrm{H}$ & $\mathrm{C}$ & $\mathrm{H}$ & $\mathrm{C}$ & $\mathrm{H}$ \\
\hline $\mathrm{i}$ & $\mathrm{i}$ & $\mathrm{s}$ & $\mathrm{s}$ & $\mathrm{s}$ & $\mathrm{s}$ & $\mathrm{i}$ & $\mathrm{i}$ & $\mathrm{s}$ & $\mathrm{s}$ & $\mathrm{i}$ & $\mathrm{i}$ & $\mathrm{s}$ & $\mathrm{s}$ & ss & ss \\
\hline \multicolumn{16}{|c|}{ solubility of cellulose nitrate in different solvents } \\
\hline \multirow{2}{*}{\multicolumn{3}{|c|}{$\begin{array}{lll}\mathrm{HNO}_{3} & \mathrm{H}_{2} \mathrm{SO}_{4} & \mathrm{H}_{2} \mathrm{O}\end{array}$}} & & \multicolumn{2}{|c|}{ Acetone } & \multicolumn{2}{|c|}{ Ethanol } & \multicolumn{2}{|c|}{ Ester } & \multicolumn{2}{|c|}{ Benzene } & \multicolumn{2}{|c|}{ Pyridine } & \multicolumn{2}{|c|}{ 1,4-dioxan } \\
\hline & & & & $\mathrm{C}$ & $\mathrm{H}$ & $\mathrm{C}$ & $\mathrm{H}$ & $\mathrm{C}$ & $\mathrm{H}$ & $\mathrm{C}$ & $\mathrm{H}$ & $\mathrm{C}$ & $\mathrm{H}$ & $\mathrm{C}$ & $\mathrm{H}$ \\
\hline 36.03 & 55.68 & 8.30 & $80.02 \pm 2.1$ & Ss & ss & $\mathrm{i}$ & $\overline{\mathrm{i}}$ & $\mathrm{s}$ & $\mathrm{s}$ & $\mathrm{i}$ & $\overline{\mathrm{i}}$ & $\mathrm{s}$ & $\mathrm{s}$ & SS & $\mathrm{s}$ \\
\hline 37.38 & 57.93 & 4.68 & $64.20 \pm 3.2$ & ss & ss & $\mathrm{i}$ & $\mathrm{i}$ & $\mathrm{s}$ & $\mathrm{s}$ & $\mathrm{i}$ & $\mathrm{i}$ & $\mathrm{s}$ & $\mathrm{s}$ & ss & $\mathrm{s}$ \\
\hline 46.21 & 49.62 & 4.16 & $62.30 \pm 2.3$ & ss & ss & $\mathrm{i}$ & $\mathrm{i}$ & $\mathrm{s}$ & $\mathrm{s}$ & $\mathrm{i}$ & $\mathrm{i}$ & $\mathrm{s}$ & $\mathrm{s}$ & ss & $\mathrm{s}$ \\
\hline 63.00 & 35 & 2 & $71.13 \pm 4.58$ & ss & $\mathrm{s}$ & $\mathrm{i}$ & $\mathrm{i}$ & $\mathrm{s}$ & $\mathrm{s}$ & $\mathrm{i}$ & $\mathrm{i}$ & $\mathrm{s}$ & $\mathrm{s}$ & ss & $\mathrm{s}$ \\
\hline \multicolumn{16}{|c|}{$\begin{array}{llll}\mathrm{HNO}_{3} & \mathrm{H}_{3} \mathrm{PO}_{4} & \mathrm{H}_{2} \mathrm{O}\end{array}$} \\
\hline 50 & 50 & 0 & $82.02 \pm 2.0$ & ss & $\mathrm{s}$ & $\mathrm{i}$ & $\mathrm{i}$ & ss & $\mathrm{s}$ & $\mathrm{i}$ & $\mathrm{i}$ & $\mathrm{s}$ & $\mathrm{s}$ & ss & $\mathrm{s}$ \\
\hline 35 & 63 & 2 & $96.02 \pm 3.4$ & ss & ss & $\mathrm{i}$ & $\mathrm{i}$ & ss & $\mathrm{s}$ & $\mathrm{i}$ & $\mathrm{i}$ & $\mathrm{s}$ & $\mathrm{s}$ & ss & $\mathrm{s}$ \\
\hline 40 & 58 & 2 & $60.18 \pm 2.2$ & ss & $\mathrm{s}$ & $\mathrm{i}$ & $\mathrm{i}$ & ss & $\mathrm{s}$ & $\mathrm{i}$ & $\mathrm{i}$ & $\mathrm{s}$ & $\mathrm{s}$ & ss & $\mathrm{s}$ \\
\hline 63.00 & 35 & 2 & $84.05 \pm 8.72$ & ss & $\mathrm{s}$ & $\mathrm{i}$ & $\mathrm{i}$ & ss & $\mathrm{s}$ & $\mathrm{i}$ & $\mathrm{i}$ & $\mathrm{s}$ & $\mathrm{s}$ & ss & $\mathrm{s}$ \\
\hline \multicolumn{16}{|c|}{$\mathrm{HNO}_{3} \quad \mathrm{AC}_{2} \mathrm{O} \mathrm{AcOH}$} \\
\hline 50 & 25 & 25 & $40.22 \pm 1.2$ & ss & ss & ss & ss & ss & $\mathrm{s}$ & $\mathrm{i}$ & $\mathrm{i}$ & $\mathrm{s}$ & $\mathrm{s}$ & $\mathrm{i}$ & $\mathrm{i}$ \\
\hline 40 & 35 & 25 & $40.00 \pm 2.3$ & ss & ss & $\mathrm{i}$ & $\mathrm{i}$ & ss & $\mathrm{s}$ & $\mathrm{i}$ & $\mathrm{i}$ & $\mathrm{s}$ & $\mathrm{s}$ & $\mathrm{i}$ & $\mathrm{i}$ \\
\hline 63 & 32 & 5 & $20.00 \pm 0.4$ & ss & ss & $\mathrm{i}$ & $\mathrm{i}$ & ss & ss & $\mathrm{i}$ & $\mathrm{i}$ & $\mathrm{s}$ & $\mathrm{s}$ & $\mathrm{i}$ & $\mathrm{i}$ \\
\hline 63 & 32 & 2 & $35.28 \pm 5.10$ & ss & $\mathrm{s}$ & $\mathrm{i}$ & i & ss & $\mathrm{s}$ & $\mathrm{i}$ & $\mathrm{i}$ & $\mathrm{s}$ & $\mathrm{s}$ & $\mathrm{i}$ & $\mathrm{i}$ \\
\hline
\end{tabular}

$\mathrm{HNO}_{3}=$ nitric acid, $\mathrm{H}_{2} \mathrm{SO}_{4}=$ sulphuric acid, $\mathrm{H}_{3} \mathrm{PO}_{4}=$ phosphoric acid, $\mathrm{AC} \mathrm{C}_{2} \mathrm{O}=$ acetic anhydride,

ACOH = acetic acid $C=$ cold, $H=$ hot, ss = sparingly soluble, $s=$ soluble, $i=$ insoluble

Table 2. Range of nitrogen contents of cellulose nitrate produced from the different nitrating acid mixtures.

\begin{tabular}{ccc}
\hline S. No & Nitrating acid mixture & \% Nitrogen content (Fusion test result) \\
\hline 1. & $\mathrm{HNO}_{3}+\mathrm{H}_{2} \mathrm{SO}_{4}+\mathrm{H}_{2} \mathrm{O}$ & $13.06-12.40$ (Prussian blue) \\
2. & $\mathrm{HNO}_{3}+\mathrm{H}_{3} \mathrm{PO}_{4}+\mathrm{H}_{2} \mathrm{O}$ & $13.12-12.00$ (Precipitate) \\
3. & $\mathrm{HNO}_{3}+\mathrm{AC}_{2} \mathrm{O}+\mathrm{ACOH}$ & $11.77-11.2$ (Precipitate) \\
\hline
\end{tabular}

$\mathrm{HNO}_{3}=$ nitric acid, $\mathrm{H}_{2} \mathrm{SO}_{4}=$ sulphuric acid, $\mathrm{H}_{3} \mathrm{PO}_{4}=$ phosphoric acid, $\mathrm{AC}_{2} \mathrm{O}=$ acetic anhydride, $\mathrm{ACOH}=$ acetic acid 
The solubility of cellulose acetate in acetone and chloroform showed that high quality triacetates were prepared, suggesting that a cellulosic polymer made up of a number of glucose units possessing three free hydroxyl groups were extracted ${ }^{7,13}$. The general high yield of cellulose nitrate obtained with $\mathrm{HNO}_{3}+\mathrm{H}_{2} \mathrm{SO}_{4}+\mathrm{H}_{2} \mathrm{O}$ and $\mathrm{HNO}_{3}+\mathrm{H}_{3} \mathrm{PO}_{4}+\mathrm{H}_{2} \mathrm{O}$ nitrating acid mixtures showed that sawdust is a useful feedstock for the production of cellulosic pulp suitable for cellulose nitrate production. Nitration is an irreversible reaction whose rate depends chiefly on the acidity of the medium. It is most frequently carried out with a mixture of concentrated nitric acid, sulphuric acid and water $\left(\mathrm{HNO}_{3}+\mathrm{H}_{2} \mathrm{SO}_{4}+\mathrm{H}_{2} \mathrm{O}\right)$. Nitrating agent brings about esterification of the hydroxyl groups of the glucosidic monomers linked together by oxygen bridges at the 1 - and 4 - positions according to the equation (i). Nitric acid on itself contains little nitronium ion $\left({ }^{+} \mathrm{NO}_{2}\right)$, the effective electrophile but in the presence of $\mathrm{H}_{2} \mathrm{SO}_{4}$, more of the ${ }^{+} \mathrm{NO}_{2}$ is generated ${ }^{12,14,15}$.

$$
\left[\mathrm{C}_{6} \mathrm{H}_{7} \mathrm{O}_{2}(\mathrm{OH})_{3}\right] \mathrm{x}+3 \mathrm{xHONO}_{2}\left[\mathrm{C}_{6} \mathrm{H}_{7} \mathrm{O}_{2}\left(\mathrm{ONO}_{2}\right)_{3}\right) \mathrm{x}+3 \mathrm{xH}_{2} \mathrm{O}
$$

Results therefore implied that ${ }^{+} \mathrm{NO}_{2}$ generation can be enhanced using $\mathrm{H}_{3} \mathrm{PO}_{4}$ because the degree of nitration obtained from this study decreased in the order $\mathrm{H}_{3} \mathrm{PO}_{4}>\mathrm{H}_{2} \mathrm{SO}_{4}>\mathrm{AC}_{2} \mathrm{O}$. The poor performance of $\mathrm{HNO}_{3}+\mathrm{AC}_{2} \mathrm{O}+\mathrm{ACOH}$ obtained was attributed to the possibility of reduced ${ }^{+} \mathrm{NO}_{2}$ generation. Changing the water content of the nitrating acid affects the reaction equilibrium and thus the degree of nitration ${ }^{12}$, which further explains the reduced yield of $\mathrm{HNO}_{3}$ $+\mathrm{AC}_{2} \mathrm{O}+\mathrm{ACOH}$ in which water was absent. Results from this study implied that variation in the above mentioned factors easily shifts the equilibrium reaction conditions hence influencing the degree of nitration and consequently the yield and basic characteristics of products.

Solubility of cellulose nitrates is reported to be strongly dependent on the nitrogen content of the product and that ester soluble cellulose nitrates are known to have nitrogen contents above $11 \%{ }^{9,14}$. Increased solubility of products obtained using $\mathrm{HNO}_{3}+\mathrm{H}_{2} \mathrm{SO}_{4}+$ $\mathrm{H}_{2} \mathrm{O}$ and $\mathrm{HNO}_{3}+\mathrm{H}_{3} \mathrm{PO}_{4}+\mathrm{H}_{2} \mathrm{O}$ in comparison to those produced from $\mathrm{HNO}_{3}+\mathrm{AC}_{2} \mathrm{O}+$ $\mathrm{ACOH}$ in this study confirmed the fact that cellulose nitrates from $\mathrm{HNO}_{3}+\mathrm{H}_{2} \mathrm{SO}_{4}+\mathrm{H}_{2} \mathrm{O}$ and $\mathrm{HNO}_{3}+\mathrm{H}_{3} \mathrm{PO}_{4}+\mathrm{H}_{2} \mathrm{O}$ contained higher nitrogen. Furthermore, solubility results showed that these nitrocellulose products can be damped in acetone or esters for industrial applications.

Based on their nitrogen contents, products from $\mathrm{HNO}_{3}+\mathrm{H}_{2} \mathrm{SO}_{4}+\mathrm{H}_{2} \mathrm{O}$ and $\mathrm{HNO}_{3}+$ $\mathrm{H}_{3} \mathrm{PO}_{4}+\mathrm{H}_{2} \mathrm{O}$ could be useful in the production of gun cotton and pyroxylin, celluloid, collodion, plastics, lacquers and films but the products from $\mathrm{HNO}_{3}+\mathrm{AC}_{2} \mathrm{O}+\mathrm{ACOH}$ nitrating acid mixture may only be utilized in the manufacture of plastics, lacquers and films. It is good to add that cellulose nitrate of high nitrogen content $(>13 \%)$ is inflammable when dry and may explode when exposed to heat and shock so it is better stored moist or damp ${ }^{12}$ in the a suitable organic solvent.

\section{Conclusions}

This study has shown that sawdust, which constitutes an environmental problem in Nigeria due to ineffective disposal methods could be converted to cellulose nitrate polymer which has potential industrial applications. Study also showed that variation in the composition of a particular nitrating acid mixture, relative acid strength of the nitrating mixture, nitrating time and proportion of nitrating acid to cellulose material all influenced the yield and solubility of cellulose nitrate.

\section{References}

1. Okoro A, Ejike E N and Anunso C, Journal of Engineering and Applied Sciences, 2007, 2(2), 282 -285. 
2. Adekunle I M, Arowolo T A, Omoniyi I T and Olubambi O T, Chem Ecol., 2007, 23(5), 383 -392.

3. Ikem A, Osibanjo O, Sridhar M K C and Sobande A, Water Air Soil pollut., 2002, 140(1-4), 307 - 333.

4. Adekunle I M, Arowolo T A, Ndahi N P, Bello B and Owolabi D A, Annals of Environmental Science, 2007b, 1, 23-34.

5. Harris J F, Wood as a Chemical Raw Material. The Chemistry of Wood; Interscience, New York: USA, 1963.

6. Belewu M A, Afr J Biotechnol., 2006, 5(19), 1763 -1764.

7. Israel A U, Obot I B, Umoren S A, Mkpenie V and Asuquo J E, E Journal of Chemistry, 2008, 5(1), 88-85.

8. $\quad$ Oke D B and Oke M O, Research Journal of Poultry Sciences. 2007, 1(1), 12- 15.

9. David N-S H and Nobuo S, Wood and Cellulose Chemistry; $2^{\text {nd }}$ Ed., CRC Press, 2000.

10. Association of Official Analytical Chemists (AOAC), Official Methods of Analysis, $14^{\text {th }}$ Ed; Virginia, USA, 1990.

11. Ghose T K, Adv Biotech J., 1956, 2, 105 -111.

12. Whistler C, Methods in Carbohydrate Chemistry "Cellulose" Vol III; Academic Press: New York, 1963.

13. Saunders K J, Organic Polymer Chemistry; Chapman and Hall: London, 1973.

14. Hogget J G, Moodie R B, Penton J R and Schofield K, Nitration and anamatic reactivity; Cambridge University Press: London, 1971.

15. Sykes P, A Guidebook to Mechanism in Organic Chemistry; $5^{\text {th }}$ Ed.; Longman: London, 1980. 


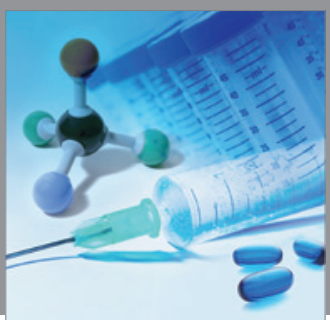

International Journal of

Medicinal Chemistry

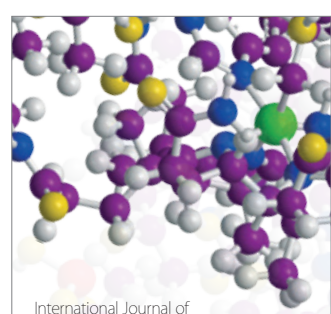

Carbohydrate Chemistry

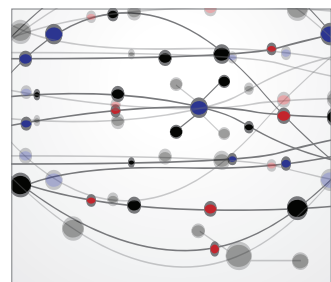

The Scientific World Journal
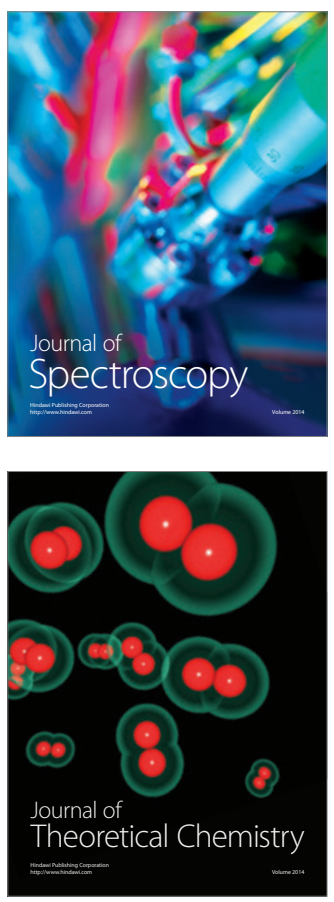
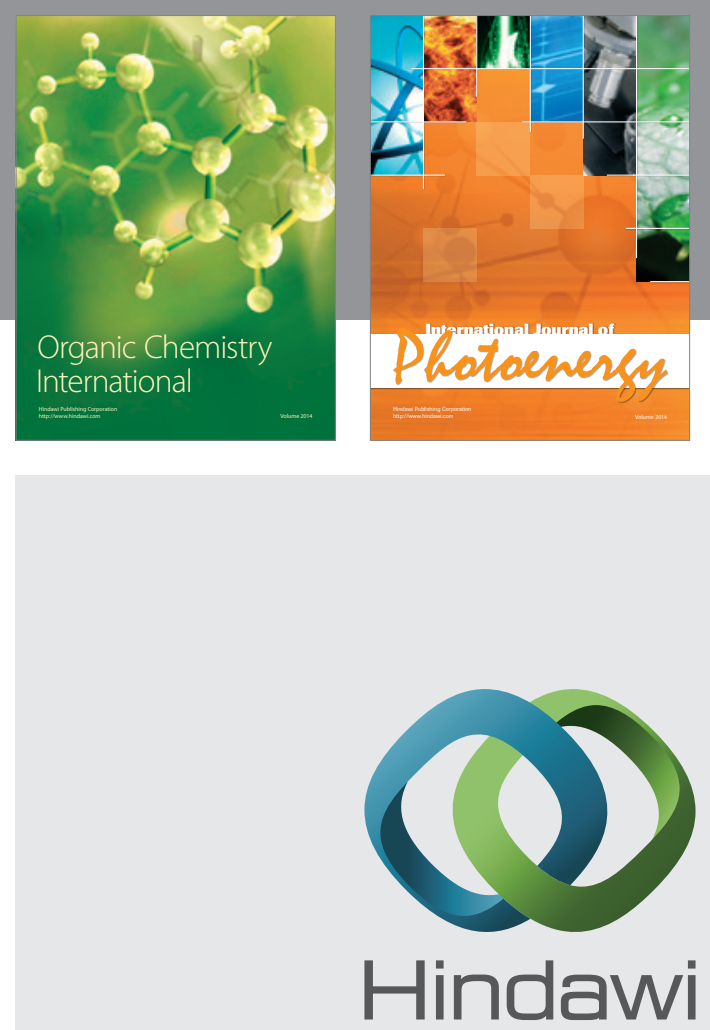

Submit your manuscripts at

http://www.hindawi.com
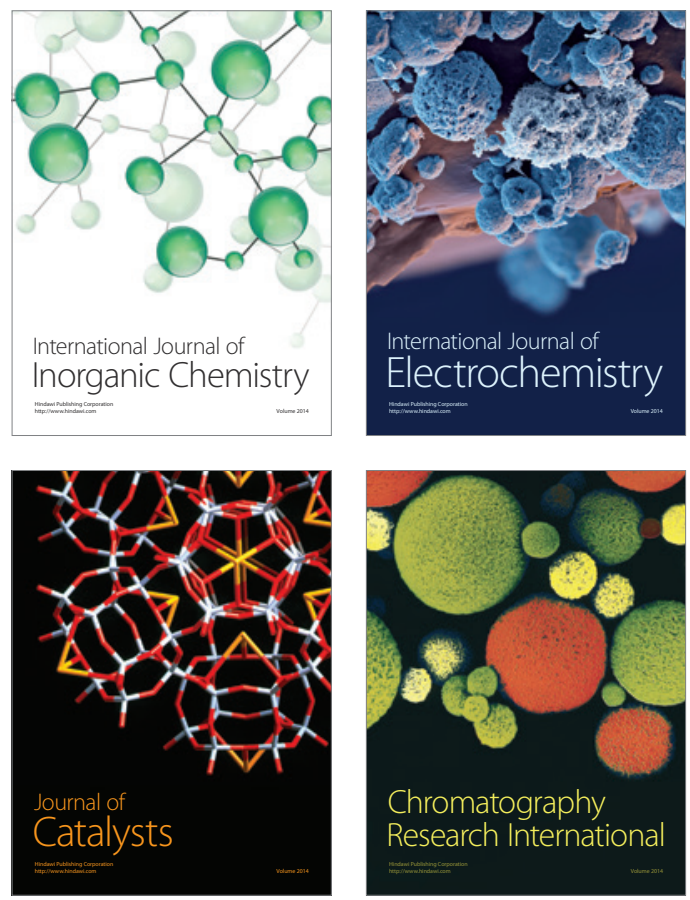
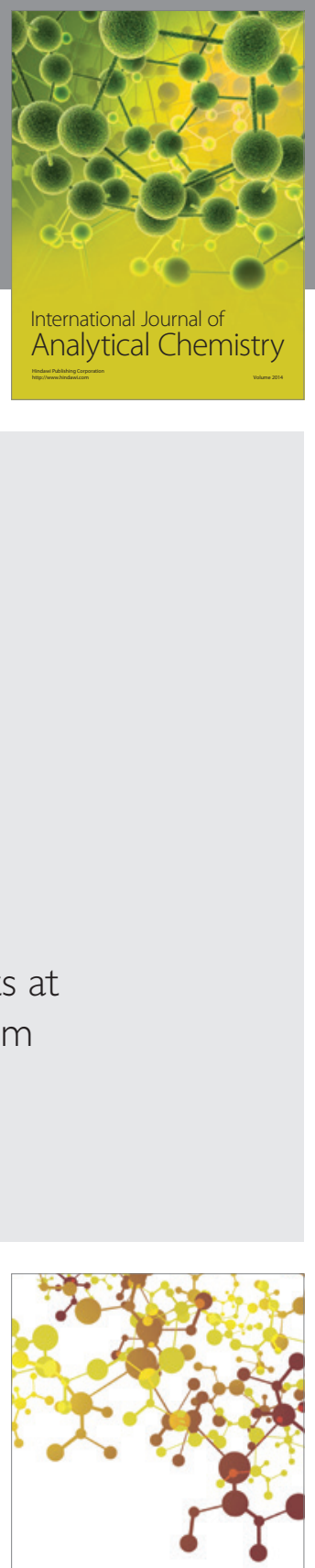

Journal of

Applied Chemistry
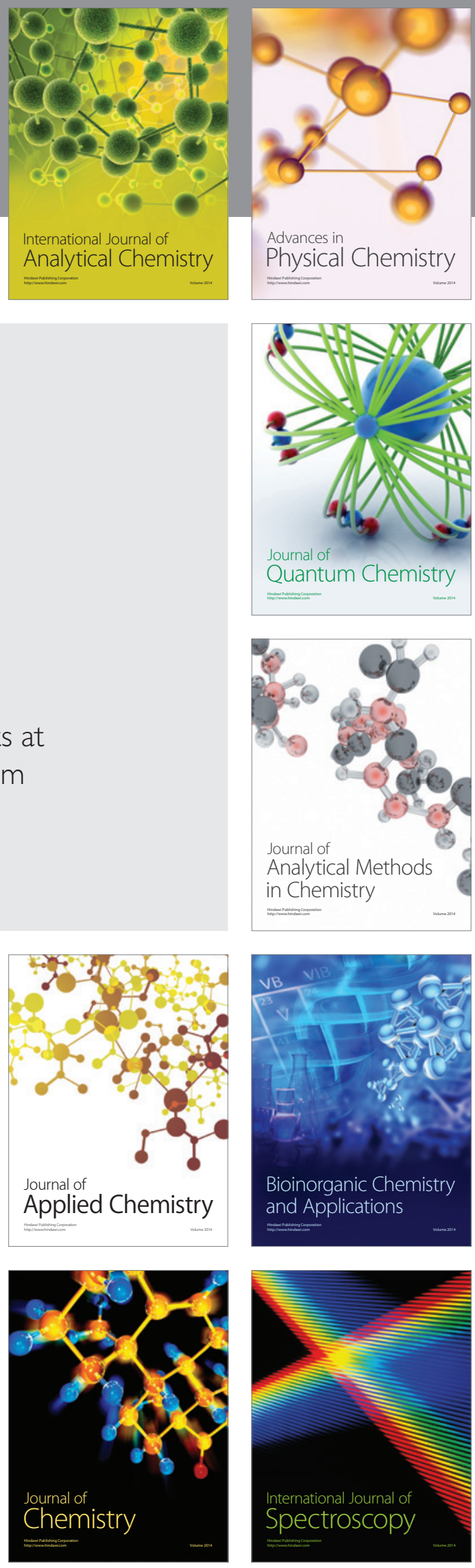